\title{
A QUESTÃO DA NATUREZA NOS DISCURSOS SOBRE AS CIÊNCIAS E AS ARTES E A DESIGUALDADE
}

\author{
Manoel Dionizio Neto ${ }^{1}$
}

\begin{abstract}
Resumo:
No Discurso sobre as ciências e as artes, Rousseau diz que as ciências e as artes contribuíram para a corrupção dos costumes. O que tem a ver a corrupção dos costumes com a natureza conforme expôs neste Discurso? Há vínculo entre a natureza em geral e a natureza humana? Qual a relação entre vícios e virtudes e a natureza? Esta natureza é a mesma referida no Discurso sobre a desigualdade entre os homens? Ele fala do que o homem fez de si mesmo com a passagem do estado de natureza ao estado civil e dos costumes que se degradaram com o desenvolvimento das ciências e das artes. O que tudo isso tem a ver com a natureza? É o que nos dizem os Discursos aqui referidos, permitindo-nos pensar na significação da desigualdade moral da mesma forma que pensamos nos vícios e na ausência das virtudes pelo restabelecimento das ciências e das artes.
\end{abstract}

Palavras-Chave: Natureza. Costumes. Vícios. Virtude. Desigualdade humana.

\section{THE NATURE ISSUE IN THE DISCOURSES ON THE ARTS AND SCIENCE AND ON THE INEQUALITY}

\begin{abstract}
:
In the Discourse on the arts and sciences, Rousseau says that science and arts contributed to the corruption of customs. What does the corruption of customs have to do with nature, as expounded in this Discourse? Is there a link between nature in general and human nature? What is the relationship between vices and virtues and the nature? Is this nature the same mentioned in the Discourse on the origin and basis of inequality among men? It speaks of what man has made of himself with the passage from the state of nature to the civil state and the customs that have degraded with the development of science and arts. What does all this have to do with nature? This is what those Discourses tell us, allowing us to think about the significance of moral inequality as we think about vices and the absence of virtues through the restoration of science and arts.
\end{abstract}

Keywords: Nature. Customs. Vices. Virtue. Human inequality

\section{Introdução}

Não há como refletir sobre a realidade humana sem considerar a sua relação com a natureza e a cultura. Perguntamos então pela diferença entre o natural e o cultural no homem. Qual então a possível dificuldade para se distinguir, no mundo civilizado de hoje, o natural do artificial, quando o ser humano se faz um ser de cultura? Se tomarmos apenas o

1 Graduado em Filosofia pela UFPE (Licenciatura e Bacharelado), Mestrado em Filosofia pela UFPB e Doutorado em Educação pela UFSCar, é Professor Associado IV na Unidade Acadêmica de Ciências Sociais do Centro de Formação de Professores da UFCG (Universidade Federal de Capina Grande). Atua como professor de Filosofia e tem como referência o pensamento de Rousseau e a Teoria Crítica, com ênfase em Marcuse, Adorno e Horkheimer, bem como o existencialismo e a fenomenologia, ressaltando-se Sartre e Merleau-Ponty. Contato: dionizioneto@uol.com.br. 
mundo em que estamos inseridos, damo-nos conta de que ele se faz, sim, pelo que é obra do próprio homem, mas também, e antes de tudo, pelo que está posto sem a necessária interferência humana. Contemplando, então, esse mundo assim constituído, concordamos com a observação de Jacques Monod (1975, p. 15): “A distinção entre objetos artificiais e objetos naturais parece a cada um de nós imediata e sem ambiguidade. Rochedo, montanha, rio ou nuvem, são objetos naturais; uma faca, um lenço, um automóvel, são objetos artificiais”. Todavia, quando a questão se volta para o próprio homem, não é assim tão simples. Considerando a natureza não projetiva, ao contrário da produção humana, mas pensando na sua objetividade, pergunta Monod (MONOD, 1975, p. 16): "seria possível definir com critérios objetivos e gerais as características dos objetos artificiais, produtos de uma atividade projetiva consciente, por oposição aos objetos naturais resultando do jogo gratuito das forças físicas?"

Ressaltamos assim a dificuldade que se tem para se distinguir, no próprio homem, o natural do que é sua invenção. Esta questão foi posta por Lévi-Strauss, perguntando pelo que deveria se tomar como natural com vista ao que se tem como determinante à regulamentação dos costumes no âmbito da civilização. Reportando-nos a Aristóteles, encontramos o ser humano como um ser naturalmente social ou político. ${ }^{2}$ Com isto somos levados a pensar a cultura como o que tem que ser no âmbito do humano, enquanto se entende por natureza aquilo que não depende da intervenção humana. Assim, o homem tem que ser necessariamente cultural, porque obrigatoriamente vive em uma cidade; tem a obrigação de viver com os outros demarcando a obrigatoriedade do convívio social que ele próprio criou. Aristóteles pergunta pelo que poderia ser um indivíduo fora do meio social, não habitando à pólis. Seria isto inconcebível ao ser humano, porque não seria possível a vida humana fora da polis, pois o homem é naturalmente político. Mas contrariam este entendimento Hobbes e Rousseau. Hobbes, segundo João Paulo Monteiro (1999, p. 13-14), diz ser a "maior parte dos filósofos políticos, que acreditam haver no homem uma disposição natural para viver em sociedade". E acrescenta: "Na obra Sobre o Cidadão Hobbes argumenta contra Aristóteles

2 Hanna Arendt chama a atenção para o equívoco da tradução latina, quando diz ter sido de Aristóteles a afirmação de que o homem é naturalmente social. Aristóteles, segundo ela, nem teria por que fazer esta afirmação, uma vez que considerava o homem um animal dentre outros que vivem naturalmente em sociedade. Neste sentido, vale considerar o equívoco em se identificar o social com o político. Ou seja, remete-nos ao pensamento aristotélico a peculiaridade do homem como ser político, distinguindo-se, portanto, dos que são apenas sociais. A propósito disto, afirma: "É somente com o ulterior conceito de uma societas generis humani, uma 'sociedade da espécie humana', que o termo 'social' começa a adquirir o sentido de condição humana fundamental. Não que Aristóteles ou Platão ignorasse ou não desse importância ao fato de que o homem pode viver fora da companhia dos homens; simplesmente não incluíam tal condição entre as características especificamente humanas" (ARENDT, Hannah, 2000, p. 32-33).

\begin{tabular}{|l|l|l|l|l|}
\hline Rovita Dialectus & Ano 8 & n. 15 & Agosto-Dezembro 2019 & p. $181-202$ \\
\hline
\end{tabular}


[...], para quem o homem é um animal social e já estava naturalmente incluído numa ordem ideal". E conclui: “Os homens vivem em cooperação natural, como o fazem as abelhas ou as formigas. O acordo entre elas é natural; entre os homens, só pode ser artificial” (Ibidem, p. 14). Jean-Jacques Rousseau, mesmo concordando com Hobbes, tem outro entendimento a respeito da natureza em relação aos homens e às suas intrínsecas relações. É disto, pois, que procurarmos tratar aqui.

Para nos certificarmos dessa distância entre Rousseau e Aristóteles que diz ser o homem, por natureza, um ser social, e entre ele e Hobbes, que pensou o estado civil e descreveu o estado de natureza, tomamos o Discurso sobre as ciências e as artes e o Discurso sobre a origem e os fundamentos da desigualdade entre os homens para tratarmos do Rousseau sobre a ciência e as artes em sua relação com a natureza e a desigualdade humana.

Em ambos os Discursos, Rousseau fala dos costumes. Estes estão sempre associados ao que sabemos da cultura que se firmou com a passagem do estado de natureza ao estado civil. Mas, no Primeiro Discurso, ele não faz nenhuma referência a esta passagem. Seria possível então relacionar a corrupção dos costumes referida neste Discurso com a desigualdade humana de que trata no Segundo?

Tomando então como referência esses Discursos, discorremos sobre as questões que norteiam as reflexões de Rousseau tendo por base a natureza, sendo esta também objeto de reflexão de outros filósofos, como Hobbes e Locke, que procuram o significado da Natureza e da Lei Natural. Diz Robert Derathé (2009, p. 193) que, “desde a segunda metade do século XVII, a hipótese do estado de natureza torna-se um lugar-comum da filosofia política". E a isto, acrescenta: "Não encontramos somente em Hobbes e Locke, mas também em Pufendorf, Burlamaqui, Wolff e em todos os jurisconsultos da escola do direito natural" (Ibidem). Portanto, Rousseau juntou-se a estes para também refletir sobre a Natureza. Daí tomamos os Discursos de Rousseau como base para toda discussão possível a este respeito da natureza em geral e da natureza humana em particular, bem como sobre a natureza em relação aos costumes e a virtude, ao tempo em que nos voltamos para o pensamento de Rousseau sobre as diferentes formas de desigualdade entre os homens, tendo a corrupção dos costumes como abertura para os vícios com o desenvolvimento da ciência e da tecnologia e, por fim, sobre a relação entre a desigualdade moral entre os homens e a natureza. Ou seja, questões que, para Rousseau, não poderiam ser concebidas sem pensar na significação da natureza e da sociedade.

\begin{tabular}{|l|l|l|l|l|}
\hline Qovista Qialectus & Ano 8 & n. 15 & Agosto - Dezembro 2019 & p. $181-202$ \\
\hline
\end{tabular}




\section{A natureza em geral e a natureza humana em particular}

A discussão acerca da natureza em geral e da natureza humana em particular nos remete aos primórdios da humanidade. Sistematizando essa discussão, os homens, direta ou indiretamente, refletiram sobre a natureza, considerando os seus contornos e o que eles próprios são ou que poderiam ser. Por isso, seja no âmbito da mitologia ou da ciência, os homens se debatem sobre a natureza, ressaltando o empírico e o teórico. Assim o pensamento humano se faz na sua forma mais ingênua ou espontânea de ser, mas também no seu modo mais sistematizado como conhecimento científico ou filosófico.

Como Rousseau concebeu a natureza e, de forma mais específica, o estado de natureza em sua contraposição ao estado civil? Como ele pensou a natureza humana, estando homem vivendo em sociedade ou simplesmente isolado em um mundo natural? Rousseau contraria o exposto por Aristóteles e os seus seguidores. Pois, mesmo que concordemos com Hannah Arendt, para quem há um equívoco de tradução do pensamento de Aristóteles na afirmação de que o homem é naturalmente social, o que afirmou este filósofo, ou mesmo Platão, não altera o entendimento de que, segundo os gregos, o homem é naturalmente social. Isto porque, o fato de não ser ele o único a viver necessariamente em sociedade, não nega o fato de ser ele também social, assim como outros animais de outras espécies, como as abelhas e as formigas.

Essa discussão, expressiva entre os gregos, fora retomada pelos iluministas a partir do século XVII, na Inglaterra, enfatizando-se no século XVIII, na França. Como um dos temas presentes no âmbito das contestações do Antigo Regime, a natureza passou a ser referência a uma série de conceitos para uma nova compreensão de mundo. Montesquieu, por exemplo, refere-se ao homem como um "ser físico" à semelhança de outros corpos que são governados por leis. No entanto, essas leis, estabelecidas por Deus ou pelo próprio homem, são violadas ou transformadas pelo próprio homem. Ele lembra ainda que o ser humano é sensível e está "sujeito a mil paixões"; por isso Deus lhe chamou para si com as leis da religião, da mesma forma que os filósofos o chamaram com as leis da moral. Daí conclui que o homem é naturalmente social: "Feito para viver na sociedade, poderia nela esquecer-se dos outros; os legisladores fizeram-no voltar a seus deveres com as leis política e civis" (MONTESQUIEU, 1999, p. 13). Essas leis, são antecedidas pelas leis da natureza: “Antes de todas estas leis, estão as leis da natureza, assim chamadas porque derivam unicamente da

\begin{tabular}{|c|c|c|c|c|}
\hline Qenista Dialectus & Ano 8 & n. 15 & Agosto - Dezembro 2019 & p. $181-202$ \\
\hline
\end{tabular}


constituição de nosso ser". E conclui: "Para bem conhecê-las, deve-se considerar um homem antes do estabelecimento das sociedades. As leis da natureza serão aquelas que receberia em tal estado" (Id. Ibidem, p. 13-14).

Esta última afirmação nos leva a duas questões: Se o homem antecede o estabelecimento das sociedades, seria possível afirmar ter sido ele social mesmo antes da existência das sociedades? Seria possível afirmar que as leis da natureza já existiam em um possível estado de natureza? Montesquieu diz que o homem recebeu essas leis naturais no estado de sociedade. Porém não é possível afirmar, segundo ele, que o homem tenha sempre habitado um mundo social. Então os homens só poderiam receber essas leis vivendo em sociedade. No entanto, há de se considerar que, primeiro, Montesquieu parte da questão da natureza para elaborar o seu pensamento a partir do espírito das leis, permitindo-se assim pensar criticamente a sociedade do seu tempo; segundo, junta-se aos filósofos que, a exemplo de Locke, vinham pensamento criticamente a sociedade do seu tempo. Chegamos assim a Rousseau, que critica às artificialidades desse mundo, enveredando pela reflexão sobre as ciências e as artes a partir do que estava sendo operado pelos homens em nome dessa razão que a todos encantava ao tempo que mostrava novos caminhos a seguir.

Propomo-nos então considerar o que fora refletido por Rousseau, ao tempo em que propôs novas saídas em meio a tudo que vinha sendo exposto pelos iluministas. Assim vale considerar o que ele concebeu como natureza, procurando interpretar o mundo em que se encontra com os seus contemporâneos, bem como o próprio homem. Daí fazer sua a máxima socrática: Conhece-te a ti mesmo! Mas, tomando-se as suas obras como base, se seria possível afirmar que a natureza e o homem já estavam postas em sua reflexão no seu Primeiro Discurso ao discorrer sobre $a$ ciência e as letras?

\subsection{A questão da natureza no Discurso sobre as ciências e as artes}

Rousseau nos diz em suas Confissões ter divisado outro universo e ter se transformado em outro homem ao se deparar com a proposta da Academia de Dijon para o prêmio de 1750: saber se o progresso das ciências e das artes tinha contribuído para corromper ou para apurar os costumes. Em resposta à Academia de Dijon, opta pela negativa, sustentando que as ciências e as artes contribuíram muito mais para a degradação dos costumes. Qual a relação dessa "degradação dos costumes" com a natureza, bem como

\begin{tabular}{|c|c|c|c|c|}
\hline Qovista Dialectus & Ano 8 & n. 15 & Agosto - Dezembro 2019 & p. $181-202$ \\
\hline
\end{tabular}


com as ciências e as artes? E há alguma relação entre a natureza em geral e a natureza humana, quando ele trata dos vícios e das virtudes?

Vale considerar a sutileza com que esta questão aparece pela primeira vez. Ainda não há uma exposição de conceitos que possam culminar no que o autor pretende afirmar como natureza. Todavia, adentrando na sutileza do seu discurso, é possível dialogar com ele a partir da palavra sentimento: ele diz que, estando perante o tribunal, teme pela composição do seu Discurso, não pelo sentimento. Destaque-se aqui o termo sentimento, porque, com ele, Rousseau se refere ao que ele poderia ter como opinião sobre o assunto que iria expor.

A sutileza a que nos referimos diz respeito ao modo como chega à natureza pela questão do sentimento. Esta palavra sentimento chama a atenção porque está associada aos aspectos físicos do homem. Neste sentido, vale considerar a significação do termo para o que se pode saber a respeito da natureza compreendida em seu sentido macro e micro. Partimos então dessa associação entre sentimento e natureza conforme o exposto pelo próprio Rousseau (1999, p. 186): “A esse motivo, que me encoraja, junta-se um outro, que me incita - é que, depois de ter sustentado, de acordo com minhas luzes naturais, o partido da verdade seja qual for meu sucesso, há um prêmio que não poderá faltar-me e que encontrarei no fundo do coração".

O que são essas luzes naturais? Rousseau nos lembra Agostinho, que pensa o conhecimento como luzes advindas de Deus para nós, assim como lembra Descartes, que diz em seu Discurso do método que o bom senso natural é comum a todos os homens. Portanto, por luzes naturais, Rousseau compreende a capacidade de reflexão comum a todos nós e que chega a nós espontaneamente como manifestação da natureza. Esta atenção para a natureza, ainda implícita, efetiva-se notoriamente quando entra em cena como objeto de reflexão. Confirma-se isto quando Rousseau se refere a um "espetáculo grandioso e belo" estabelecido pelo homem ao sair praticamente do nada para fazer desparecer "as trevas nas quais o envolveu a natureza", o que fez "por meio das luzes de sua razão". E assim elevou-se "acima de si mesmo", lançando-se, "pelo espírito, às regiões celestes", e recorrendo "com passos de gigante, como o sol, a vasta extensão do universo". Além disso, "o que é ainda maior e mais difícil", penetrou "em si mesmo para estudar o homem e conhecer sua natureza, seus deveres e seu fim” (ROUSSEAU, 1999, p. 198).

Deparamo-nos assim com a natureza, o homem e as relações que este estabelece com a natureza e consigo mesmo. Essas relações se dão quando ele adentra à natureza para conhecê-la, à medida que vai se deslumbrando com a sua beleza e beneficiando-se de tudo

\begin{tabular}{|l|l|l|l|l|}
\hline Qovista Dialectus & Ano 8 & n. 15 & Agosto - Dezembro 2019 & p. $181-202$ \\
\hline
\end{tabular}


aquilo que ela pode lhe oferecer. Mas também impulsionado pela sua capacidade de conhecer, lança-se sobre a natureza, elevando-se acima de si mesmo, dando-se conta de que é possível conhecer a si mesmo, por mais difícil que isso possa ser. E no âmbito dessa possibilidade de autoconhecimento, vê-se a si mesmo como parte da natureza em que ele adentra, tornando-se assim possível saber das leis pelas quais devem se orientar os homens assim como tudo que se firma na ordem daquilo que deve necessariamente ser.

No entanto, a possibilidade de conhecimento do homem sobre si mesmo deixa sempre margens para outros entendimentos., ao tempo em que persiste a autoconhecimento. Isto nos remete à lembrança de Battista Mondin sobre a afirmação de Heidegger a respeito dos avanços e da facilidade que se tem hoje para o conhecimento do homem, pois segundo este filósofo, nunca foi possível "apresentar o seu conhecimento acerca do homem de modo tão eficaz e fascinante, nem comunicá-lo de modo tão fácil e rápido. Mas também é verdade que nenhuma época soube menos que a nossa o que é o homem" (HEIDEGGER apud MONDIN, 2008, p. 8). ${ }^{3}$ Semelhante entendimento vemos em Ernst Cassirer (1977), quando afirma ser cada vez mais crescente o conhecimento que o homem tem sobre si mesmo, mas não suficiente para responder o que ele seja. Daí a referência ao "homo abscondituus" de Pascal conforme as palavras de Cassirer (1977, p. 22) ou ao "complexo humano" visto por Edgar Morin (2012).

\subsection{A natureza para Rousseau e o jusnaturalismo}

Tendo a natureza como objeto de sua reflexão para a compreensão dos feitos humanos como ciência, arte ou tudo que diga respeito à cultura, Rousseau situa-se entre os que fizeram a escola jusnaturalista, tomando a natureza como algo fundamental para a autoafirmação do homem como condição de sua emancipação. Todavia, ele está para o jusnaturalismo como está para a modernidade. Alain Touraine (1995, p.28), ao situá-lo na modernidade, vê o pensamento dele como "a primeira grande crítica interna da modernidade", conclamando "à harmonia da natureza contra a confusão e desigualdade sociais”. Assim também podemos situá-lo entre os jusnaturalistas, considerando a crítica que ele faz aos

3 Assim como Mondin, Edgar Morin (2012, p. 16) recorre às mesmas palavras de Heidegger para falar da inibição criada pelo modo de conhecer adotado pelos homens pera conhecer o complexo humano: "Nenhuma época acumulou sobre o homem tão numeroso e diversos conhecimentos como a nossa (...) Nenhuma época conseguiu tornar esse saber tão pronta e facilmente acessível. Mas nenhuma época tampouco soube menos o que é o homem" (HEIDEGGER apud MORIN, 2012, p. 16).

\begin{tabular}{|l|l|l|l|l|}
\hline Govista Qialectus & Ano 8 & n. 15 & Agosto - Dezembro 2019 & p. $181-202$ \\
\hline
\end{tabular}


defensores do direito natural, sendo um de seus representantes Thomas Hobbes. Pois, no Discurso sobre a desigualdade, diz que "Hobbes viu muito bem o defeito de todas as definições modernas de direito natural, mas as conseqüências, que tira das suas, mostram que o tomam num sentido que não é menos falso" (ROUSSEAU, 1991, p. 252).

Rousseau chega a essa conclusão depois de verificar que Hobbes concluiu que "o homem é naturalmente mau" "por não ter nenhuma idéia da bondade", assim como afirma ser o homem corrupto por não conhecer a virtude e que, entre outras coisas, "devido ao direito que se atribui com razão relativamente às coisas de que necessita, loucamente imagine ser o proprietário do universo inteiro" (Id., ibidem). Ainda, observa Robert Derathé, Rousseau não consegue admitir que a natureza dispusesse de uma espécie que tivesse por fim a sua própria destruição; ao contrário, para ele, quis a natureza que houvesse a conservação tanto dos indivíduos quanto da sua espécie, e se pergunta pela possibilidade de alguém, como Hobbes, ter afirmado o contrário (Cf. DERATHÉ, 2006, p. 2010). Nisto está, como se percebe, não só uma forma diferente de pensar a natureza e o próprio homem como ser natural, mas um modo contraposto ao entendimento hobbesiano, que era jusnaturalista. Portanto, ao se falar de direito natural de que se ocupava o jusnaturalismo, é bom considerar as diferentes formas de compreendê-lo para que também se possa melhor compreender a crítica de Rousseau aos jusnaturalistas. Trata-se, pois, de concebê-lo em termos históricos ou morais, como bem o diz Lourival Gomes Machado. ${ }^{4}$ Isso, por outro lado, não afasta o entendimento de que Rousseau tenha sido um jusnaturalista, assim como a crítica que ele faz à modernidade não impede a sua inserção entre os filósofos modernos, estando ele entre os iluministas.

Como vemos, Rousseau se afasta do jusnaturalismo que tem como um dos princípios a sociabilidade natural, como o vemos em Grotius e Pufendorf, por exemplo. Derathé observa em relação a isso que, no Discurso sobre a desigualdade, contrariando esses jusnaturalistas, Rousseau exclui do direito natural "a noção de sociabilidade", ao tempo em que diz estar fundamentado esse direito no amor de si e na piedade natural, que são dois princípios anteriores à razão. E isto significar dizer do distanciamento entre o homem natural e o amor-próprio, que se vincula à sociabilidade humana. Esta vinculação entre amor-próprio

4 "Coloca-se o problema do direito natural em seus verdadeiros termos, que são de duas ordens distintas: 1) históricos, pois o jusnaturalismo destinava-se precipuamente a restabelecer a obediência à ordem natural, que, por sua vez, melhor se exprimira no estado de natureza, como é óbvio; 2morais, que interessavam especialmente a Rousseau, para quem o direito moral constituiria uma compensação à fria mecânica da lei civil. [...]. Até hoje, esses dois sentidos do direito natural são permanentes e, ao menos no que tange ao direito internacional, operantes" (Nota 100, in: ROUSSEAU, 1991, p. 270).

\begin{tabular}{|c|c|c|c|c|}
\hline Qenista Dialectus & Ano 8 & n. 15 & Agosto - Dezembro 2019 & p. $181-202$ \\
\hline
\end{tabular}


e sociabilidade se faz notar quando se quer o favorecimento de si mesmo pelos serviços dos outros. Com vista nisto, Derathé (2006, p. 200) diz que Rousseau, contrariando Pufendorf, afirma não ser “a conformidade de uma mesma natureza' que nos aproxima dos nossos semelhantes, "mas a vantagem que esperamos obter de seus bons serviços. Só nos tornamos sociáveis quando não podemos mais dispensar a assistência dos outros homens". Todavia, estando ele entre os naturalistas, defensores, portanto, do direito natural, esteve voltado para a questão da natureza, procurando compreendê-la nela. Portanto, não temos como ignorar o que ele pensou sobre essa questão explorada pelos iluministas, tendo na Enciclopédia um espaço apropriado para a exposição de suas ideias.

\subsection{A natureza e o conhecimento de si mesmo}

Tendo a natureza como o que é comum aos homens, Chevalier de Jaucourt se refere- à igualdade como algo necessário e, portanto, "princípio e o fundamento da liberdade". E essa igualdade se verifica no nascimento, crescimento, subsistência e morte, permitindo-nos falar de igualdade natural ou moral. Sendo a natureza a mesma para todos os homens, "é claro que, segundo o direito natural, cada um deve estimar e tratar os outros como seres que lhes são naturalmente iguais, ou seja, homens tanto quanto ele" (JAUCOURT. 2002, p. 193). Rousseau, de algum modo, segue esse entendimento, apesar de divergir quanto à lei natural: "uma lei que Deus impõe a todos os homens e que eles podem descobrir através das luzes de sua razão, considerando atentamente sua natureza e seu estado" (Id., idem, 2007, p. 197). Para Rousseau, essa lei não seria perceptível no estado de natureza, mas somente na sociedade civil. Pois, como diz Derathé (2009, p. 236), “a lei natural, tal como foi concebida pelos filósofos e pelos jurisconsultos, essa reta razão da qual falam Cícero e Pufendorf, não poderia ser aplicada ao estado de natureza". Portanto, já no Primeiro Discurso, Rousseau se volta para a natureza. Segundo ele, os homens puderam se lançar aos confins do universo, rompendo as trevas em que estiveram envolvidos pela natureza de que são partes. Assim, o homem deveria ser concebido em sua essência. Competia-lhe então pensar o homem a partir do que houvesse de mais puro nele, razão pela qual afirma o seguinte: "O homem de bem é um atleta que se compraz em combater nu; despreza todos esses ornamentos vãos, que dificultam o emprego de suas forças e cuja maior parte só foi inventada para esconder uma deformidade qualquer" (ROUSSEAU, 1999, p. 191).

Referindo-se assim indiretamente à natureza, Rousseau traz à reflexão uma profunda compreensão do significado da condição humana. O corpo nu é expressão dessa

\begin{tabular}{|l|l|l|l|l|}
\hline Qovista Dialectus & Ano 8 & n. 15 & Agosto - Dezembro 2019 & p. $181-202$ \\
\hline
\end{tabular}


natureza como exposição do que não fora produzido originariamente pelo homem, sem interferência humana para remodelá-lo segundo o padrão requerido pelos diferentes modos de comportar-se, diante das exigências culturais que podem envolver aspectos religiosos ou imposições ideológicas que têm no consumo um grande referencial para as diferentes padronizações de beleza. O corpo nu, compreendido em sua originalidade, não pode ser excluído do que é verdadeiramente natural. Assim a nudez expressa o modo de ser próprio da personalidade de cada um, como manifestação da individualidade demonstrada nas diferentes formas de agir ou de se relacionar com os outros ou com o seu meio. Neste sentido, a natureza indica o que é próprio do ser humano. Isto nos remete ao que está no além da física, porque somente podemos pensar em termos de moralidade que se funda em valores com que se julga o indivíduo. Assim, a ideia de natureza é exposta por Rousseau tanto em sentido geral como também enquanto natureza humana, compreendida como essência que se manifesta no modo de ser de cada um dos humanos. Daí a referência de Rousseau às vestes que cobrem as deformidades do corpo da mesma forma que as hipocrisias guardam o que esconde os seus vícios, confundindo-os com as virtudes. A roupa simboliza então a hipocrisia que esconde o verdadeiro homem. As pessoas têm procurando esconder das outras a sua personalidade, recorrendo às diferentes formas de vestir. Por este vestir, chegamos à compreensão do que está posto como preconceitos e vícios. ${ }^{5}$

O homem, no desvelar-se, adentra à natureza, colocando-se acima de si mesmo. Daí a afirmação de Rousseau (1991, p. 227 - em itálico no texto consultado): “O mais útil e o menos avançado de todos os conhecimentos humanos parece-me ser o do homem e ouso afirmar que a simples inscrição do templo de Delfos continha um preceito mais importante e mais difícil que todos os grossos livros dos moralistas". Ou seja, ele retoma o "Conhece-te a ti mesmo" socrático. E para que o homem pudesse chegar ao conhecimento de si mesmo, seria necessário voltar-se para a natureza, procurando discernir o que há de natural e de artificial no mundo, onde não fica nada como saiu das mãos do autor de todas as coisas (ROUSSEAU, 1995). ${ }^{6}$ Rousseau, procurando afastar do homem tudo que foi adquirido na e com a

\footnotetext{
5 A Noutras palavras, é o que afirma o próprio Rousseau (1999, p. 191): “A riqueza do vestuário pode denunciar um homem opulento, e a elegância, um homem de gosto; conhece-se o homem são e robusto por outros sinais - é sob o traje rústico de um trabalhador e não sob os dourados de um cortesão, que se encontrarão a força e o vigor do corpo. A aparência não é menos estranha à virtude, que constitui a força e o vigor da alma".

6 "TUDO É CERTO em saindo das mãos do Autor das coisas, tudo degenera nas mãos do homem" (ROUSSEAU, 1995, p. 9).

\begin{tabular}{|l|l|l|l|l|}
\hline Qevista Dialectus & Ano 8 & n. 15 & Agosto - Dezembro 2019 & p. $181-202$ \\
\hline
\end{tabular}
}


civilização, isto é, no e com o convívio social de que ele próprio é inventor, faz a seguinte afirmação:

\begin{abstract}
E como o homem chegará ao ponto de ver-se tal como o formou a natureza, através de todas as mudanças produzidas na sua constituição original pela sucessão do tempo e das coisas, e separar o que pertence à sua própria essência daquilo que as circunstâncias e seus progressos acrescentaram a seu estado primitivo ou nele mudaram? (ROUSSEAU, 1991, p. 227 - em itálico no texto consultado).
\end{abstract}

Trata-se aqui da necessidade do homem voltar-se para si mesmo, procurando verse em sua origem, isto é, no modo como fora formado pela natureza, sem nenhuma das alterações feitas pelos homens. Assim, segundo Rousseau, nós, seres humanos, fomos formados pela natureza, o que significa dizer que somos sua criatura. Sendo a natureza criadora, nós e uma infinidade de criaturas somos seres naturais. Ou seja, sendo as coisas naturais derivadas da natureza, são criaturas, enquanto a natureza é criadora. Estabelece-se assim uma discussão que nos remete aos medievais, que procuraram distinguir a criatura do criador, entendendo por criador a natureza não criada, sendo as criaturas concebidas como a natureza criada pela natureza criadora. ${ }^{7}$ Para Rousseau, cabe ao homem remeter-se às suas origens para discernir o que lhe é próprio daquilo que ele mesmo inventou.

Reportando-se a essas origens, é possível ao homem pensar-se em seu estado primitivo, que é estado de natureza referido por Rousseau e outros filósofos e juristas dos séculos XVII e XVIII. Ser natural, portanto, significa pertencer à natureza. Assim, segundo Rousseau, paras se chegar a essa condição natural do ser humano, é preciso separar o que é ou não essencial a ele, considerando as circunstâncias e os seus próprios progressos. Trata-se assim de identificar a essência do homem com a condição natural de ser, isto é, o homem em sentido original, que não é outra coisa senão o homem natural, reafirmando-se assim no Segundo Discurso o que já havia dito no Primeiro Discurso.

\title{
2. A corrupção dos costumes e os vícios
}

7 Remetemo-nos aqui à discussão promovida por Johannis Scotus Erígena, por exemplo, que, conforme observação de Michele Federico Sciacca (1967, I, p. 198), “é muito difícil de escapar ao panteísmo”, uma vez que, depois de pensar as quatro possibilidades de se pensar a natureza, pensa Deus como Natureza não criada e não criante (Natura nec creata nec creans) como sendo o próprio Deus, concebendo-se como Deus Pai a Natureza não criada e criante (Natura creans nec creata). Assim compreendendo, o Verbo, isto é, o Filho, posto como Natureza criada e criante (Natura creans creata), e os seres sensíveis como Natureza criada e não criante (Natura creata nec creans) (Cf. SCIACCA, 1967, I, p. 197-198). Até que ponto poderíamos fazer uma aproximação ou não do pensamento de Rousseau com esse panteísmo de Scotus Erígena? Eis aqui uma questão que poderia ser desenvolvida em seus termos.

\begin{tabular}{|c|c|c|c|c|}
\hline Qovista Dialectus & Ano 8 & n. 15 & Agosto - Dezembro 2019 & p. $181-202$ \\
\hline
\end{tabular}


A preocupação de Rousseau aparece no seu Primeiro Discurso, fazendo-se de forma mais expressiva no Discurso sobre a desigualdade. Nessa preocupação está uma clara conexão com o pensamento helenista, destacando-se a herança de Lucrécio e Sêneca, conforme afirma Arlei de Espíndola. Assim, encontra-se uma interseção entre o epicurismo e o estoicismo no pensamento de Rousseau que, para além de seu jusnaturalismo, firma-se como herdeiro desses helenistas. Ressalta Espíndola que, mesmo não pactuando com a ideia de plágio desses filósofos em Rousseau, é preciso reconhecer "que muitas de suas noções presentes no segundo Discours foram antecipadas por Sêneca” (2005, p. 275). Mas também se evidencia o seguinte: "Para Rousseau, o homem civilizado [...], sendo dotado de razão, tornase vítima também de paixões e de desejos artificiais, que Lucrécio já havia sugerido que precisariam ser extintos, e não se encontra mais movido só pelo anseio de se conservar" (ESPÍNDOLA, 2008, p. 47). Assim, para Espíndola, a oposição estabelecida por Sêneca e outros estoicos entre "ciência" e "virtude" "reflete-se claramente no Discurso sobre as ciências e as artes" (Id., ibidem, p. 50). Assim sendo, a reflexão de Rousseau sobre a natureza manifesta a sua herança helenística na crítica ao advento da civilização e em meio à corrução dos costumes com as ciências e as artes.

Essa relação da natureza e o restabelecimento das ciências e das artes fora ressaltada por Jean Starobinski (1991, p. 15). Rousseau, segundo ele, “começa pomposamente por um elogio da cultura”. Pois ele dá início ao seu discurso falando do espetáculo que foi ver o homem sair do nada para desvendar as trevas em que estava envolvido pela natureza, valendo-se somente do "seu próprio esforço". Porém lamenta pela situação em que os homens se encontram: quase nada sabem de si mesmos, ao tempo em que procuram conhecer o Universo. Starobinski diz se tratar de numa viravolta do discurso de Rousseau, manifestandose aí a discordância entre o ser e o parecer: "Belo efeito de retórica: um toque de varinha mágica inverte os valores, e a imagem brilhante que Rousseau pusera sob os nossos olhos não é mais que um cenário mentiroso - belo demais para ser verdadeiro" (STAROBINSKI, 1991, p. 15).

Rousseau, contrariando a expectativa iluminista, afirma que o reestabelecimento das ciências e das artes serviu para perverter os costumes e promover os vícios. Mas adverte: "Não é em absoluto a ciência que maltrato, disse a mim mesmo, é a virtude que defendo perante homens virtuosos" (ROUSSEAU, 1999, p. 185). Observa Lourival Gomes Machado (In: ROUSSEAU, 1999, Nota 2, p. 189) que, ao lado dos aplausos às maravilhas do

\begin{tabular}{|c|c|c|c|c|}
\hline Qenista Dialectus & Ano 8 & n. 15 & Agosto - Dezembro 2019 & p. $181-202$ \\
\hline
\end{tabular}


conhecimento e ao restabelecimento das ciências, "a simples indicação de que mais difícil do que conhecer o universo é 'penetrar em si mesmo para estudar o homem e conhecer sua natureza, seus deveres e seu fim' assentará as bases da crítica que, em nome da moral, Rousseau desenvolverá contra as ciências e as artes". Ou seja, Rousseau, ao responder à Academia de Dijon, "não se limita a apreciar as ciências e as artes em relação a um possível aprimoramento dos costumes, mas considera as ciências e as artes em relação aos erros e aos vícios dos homens" (DIONIZIO NETO, 2004, f. 81). Então eu afirmo: “Ao lado do brilhante desenvolvimento das ciências e das artes, teria que ser considerado o necessário conhecimento do homem sobre si mesmo. Este o mais importante. Neste teria que se fundamentar a moral, para que se pudesse falar de aprimoramento dos costumes" (id., ibidem). Mas, ao invés de buscarem a fundamentação da moral no aprimoramento dos costumes através do conhecimento do homem sobre si mesmo, preferiram cultivar pura e simplesmente a ciência sem em levar em consideração as qualidades morais. Ou como diz o próprio Rousseau (1999, p. 109): "Se a cultura das ciências é prejudicial às qualidades guerreiras, ainda o é mais às qualidades morais. Já desde os primeiros anos, uma educação insensata orna nosso espírito e corrompe nosso julgamento".

Assim os homens, procurando desvendar o Universo, desenvolveram as ciências sem se preocupar com o destino da humanidade, sem perguntar pelos rumos que podia tomar a humanidade impulsionada pelos avanços dessas ciências. Não se deram conta de ser o luxo nutrido pelas artes, da mesma forma que a história se nutre dos tiranos, das guerras e dos conspiradores, sendo isto equivalente à jurisprudência, que perderia toda razão de existir se não houvessem as injustiças dos homens. E por assim ser, segundo Rousseau (1999, p. 204), "Somente esta reflexão deveria dissuadir todo homem que procurasse seriamente instruir-se pelo estudo da filosofia". Mas o que podemos dizer das nossas artes? "Nossos jardins estão ornados de estátuas e nossas galerias de quadros. Que representam, em vossa opinião, essas obras-primas da arte exposta à admiração Pública? Os defensores da Pátria?” Ao invés disso, “Temos físicos, geômetras, químicos, astrônomos, poetas, músicos, pintores; não temos mais cidadãos ou, se nos restam alguns deles dispersos pelos nossos campos abandonados, lá perecem indigentes e desprezados" (ROUSSEAU, Ibidem, p. 210).

Considerando assim o progresso das ciências e das artes, Rousseau entendeu que ele não acrescentou em nada "à nossa verdadeira felicidade", mas, ao invés disso, corrompeu os costumes, prejudicando assim a pureza do gosto, servindo assim para a degradação da natureza ressaltada pela deformidade da alma promovida por todos os

\begin{tabular}{|c|c|c|c|c|}
\hline Qenista Dialectus & Ano 8 & n. 15 & Agosto - Dezembro 2019 & p. $181-202$ \\
\hline
\end{tabular}


progressos do conhecimento no decorrer do tempo em que se deu a passagem do estado de natureza ao estado civil, conforme o exposto no Segundo Discurso. Por isso afirma Paul Arbousse-Bastide (In ROUSSEAU, 1999, Nota 1, p. 210): “Já se vislumbra o assunto do Discurso sobre a Desigualdade". E acrescenta: "No primeiro discurso, a desigualdade é introduzida entre os homens pela supervalorização dos talentos, em detrimento das virtudes. No segundo discurso, a desigualdade aparecerá de modo inteiramente diverso" (Id., ibidem). Perpassa-se então pela ciência e a educação essa supervalorização dos talentos, em que se funda o reconhecimento das aptidões naturais desenvolvidas conforme os estímulos propostos pela educação. Isto fica mais claro no Segundo Discurso: a desigualdade entre os homens se firma pelas convenções ou autorizações dos próprios homens, tendo por base a ciência e a educação.

Trata-se então da interferência da ciência nas decisões dos homens em suas convenções, razão pela qual se faz no sentido político a desigualdade estabelecida a partir das deliberações humanas quando se tem em vista o conhecimento do que é possível ou não para o atendimento aos interesses de alguns em detrimento de outros. Nisto se firma o caráter egoísta e, portanto, moral dessa desigualdade. Egoísta, porque sabemos que, como parte desses "alguns" que se beneficiam das convenções promotoras da desigualdade, estão os próprios responsáveis pelo convencimento de que deveria ter sido feito para atender interesses humanos, que não deixam de ser os interesses deles mesmos. Certificamo-nos assim que não se trata de culpar a ciência nela mesma, mas a recorrência a ela por parte dos indivíduos que compõem a sociedade. Ou seja, como diz o próprio Rousseau (1999, p. 85): "Não é em absoluto a ciência que maltrato, disse a mim mesmo, é a virtude que defendo perante homens virtuosos".

Da ciência, chega-se à educação, objeto de crítica contundente posta no Emílio: "Enquanto permanecemos no mesmo estado, podemos conservar as [inclinações] que resultam do hábito e que nos são menos naturais. Mas desde que a situação mude, o hábito cessa e o natural se restabelece" (ROUSSEAU, 1995, p. 11). Mas o hábito, ao contrário do que dizem, não é a educação. Ao se confundir essas duas coisas - hábito e educação - a educação acaba se confundindo com adestramento, que promove o condicionamento a certas inclinações deixadas em nós pelo hábito. Nisto está o anúncio do Segundo Discurso no Primeiro, remetendo-nos à questão da educação: “É, por assim dizer, a vida de tua espécie que vou descrever de acordo com as qualidades que recebeste, e que tua educação e teus hábitos puderam falsear, mas que não puderam destruir" (ROUSSEAU,1991, p. 237). Ou seja,

\begin{tabular}{|c|c|c|c|c|}
\hline Qenista Dialectus & Ano 8 & n. 15 & Agosto - Dezembro 2019 & p. $181-202$ \\
\hline
\end{tabular}


a educação, assim como os hábitos que são convertidos nela, corrompe as qualidades humanas, deixando, no lugar das virtudes, os vícios. Firma-se assim a corrupção dos costumes como promoção desses vícios pela ciência e a educação, quando aquela se faz em conexão com esta, tendo por fim o condicionamento dos homens às convenções que eles mesmos propõem para o consentimento de todos. E com isto se estabelece as diferentes formas desigualdade entre os homens.

\section{As diferentes formas de desigualdade entre os homens}

No "Prefácio" do Discurso sobre a origem e os fundamentos da desigualdade entre os homens, Rousseau diz ser a questão proposta pela Academia de Dijon - "Qual é a origem da desigualdade entre os homens, e é ela autorizada pela lei natural?" - "uma das questões mais interessantes que a filosofia possa propor e, infelizmente para nós, como uma das mais espinhosas a que possam responder os filósofos, pois, como conhecer a fonte da desigualdade entre os homens, se não se começar a conhecer a eles mesmos?" (ROUSSEAU, 1991, p. 227 - em itálico como no texto consultado). Deparamo-nos assim com duas questões: uma das mais interessantes questões propostas pela filosofia, e uma das questões mais espinhosas a serem respondidas pelos filósofos. Assim Rousseau parte do estado de natureza, há muito considerado pelos filósofos e pelos os juristas, para responder essas questões: um estado que não existe mais nem que virar a existir e que, talvez, nem tenha existido. Mas quis Rousseau que esse estado fosse referência para compreender o estado em que se encontrava homem contemporâneo.

Deparamo-nos, pois, com preocupação de Rousseau em relação ao conhecimento que homem deveria ter de si mesmo. Por isso ele começa o seu "Prefácio" falando da necessidade desse conhecimento, fazendo-se assim a necessidade se se reportar às origens, ou seja, ao estado de natureza. E para certificar-se do que que poderia ter sido homem neste estado, Rousseau tomou como referência três tipos fundamentais de homem. Parte então do entendimento de que, em sua origem, o homem somente poderia ser compreendido como homem natural, ficando a dificuldade para distinguir, entre nós, esse homem natural do homem compreendido como homem social. Pois, entre esses dois tipos de homem, ainda é possível identificar o homem selvagem, aquele que não é mais natural, mas não é ainda o homem social que conhecemos. Olgária Matos (1978, p. 26), ao se referir ao referir-se a isso, diz que Rousseau não apresentou nenhuma solução, mas propôs “direções para abordá-la".

\begin{tabular}{|c|c|c|c|c|}
\hline Qenista Dialectus & Ano 8 & n. 15 & Agosto - Dezembro 2019 & p. $181-202$ \\
\hline
\end{tabular}


Uma dessas direções, segundo ela, seria observar "os animais em seu meio natural"; a outra, seria "estudar o homem selvagem". A isto, ela acrescenta: "tendo sempre presente que este [selvagem] já vive em sociedade e, portanto, apresenta-se já distante do seu estado natural; não é mais o 'homem natural', mas a ele se assemelha no físico e no moral, apesar da alteração dos seus traços gerais pela vida social". Assim se constatar uma aproximação bemmaior entre o homem selvagem, encontrado pelos europeus do século XVI e XVII, do que a aproximação entre o homem europeu, civilizado, e o homem selvagem das Américas colonizadas pelos europeus.

Há assim uma imensa distância entre o homem natural e o social. Em meio a esses extremos, encontra-se o caraíba, selvagem das Américas. Sobre este afirma-se como o fez Olgária Matos (1978, p. 26): “A força do selvagem, a acuidade de seus sentidos, sua nudez, sua despreocupação, suas paixões indolentes, sua diferença com relação ao futuro, tudo isto permitirá a Rousseau reconstituir o homem tal como devia ser quando 'saíra da natureza"”. Ou seja, o homem natural se identifica com a natureza. Ao sair da natureza, o homem é apenas natural. Contrapõe-se, portanto, a ele o homem social, que sai da sociedade que ele próprio inventou. Noutros termos, o homem social é uma invenção do próprio homem. Portanto, sendo social, é artificial. Por isso a afirmação de Rousseau (1991, p. 228): “não constitui empreendimento trivial separar o que há de original e de artificial na natureza atual do homem" (em itálico no texto consultado). Mas se verifica na sociedade dois tipos de desigualdade humana: uma, natural ou física; a outra, política ou moral.

\subsection{A desigualdade moral entre os homens}

Para Rousseau, a desigualdade natural é aquela que se verifica no âmbito natural ou físico entre e uma pessoa e outra. As pessoas são naturalmente diferentes. Nisto consiste a desigualdade natural entre elas, quando se trata, por exemplo, de uma ser mais alta ou mais baixa do que a outra, ou ser uma de idade diferente da outra, da mesma forma que se pode verificar as diferentes aptidões ou predisposições naturais que cada uma possa tem em relação às demais. Trata-se aqui de diferentes formas de desigualdade que se originam na natureza. Daí, segundo Rousseau, não é possível discorrer sobre a fonte dessa desigualdade. Mas o mesmo não podemos afirmar quando se trata da desigualdade moral. Pois esta, que é política, tem como fonte a convenção ou o consentimento dos homens.

\begin{tabular}{|c|c|c|c|c|}
\hline Govita Dialectus & Ano 8 & n. 15 & Agosto - Dezembro 2019 & p. $181-202$ \\
\hline
\end{tabular}


Para falar desse tipo de desigualdade estabelecida nos diferentes convívios humanos, Rousseau descreve o estado de natureza para demonstrar que, aí, os homens eram desiguais, tendo todos em comum apenas a liberdade e a perfectibilidade, e tendo o amor de si e a piedade natural como pontos de interseção entre os homens e os outros animais. Depois da descrição do estado de natureza, onde o homem se encontra isolado e nu, Rousseau passa à descrição do estado a que chegou o homem, passando por um processo de corrupção da natureza, para se firmar em sua desigualdade política que, sendo da vontade do próprio homem, é uma desigualdade moral, assim como é também física a desigualdade natural que se verifica entre os homens, seja no estado de natureza ou no estado civil.

Rousseau introduz a discussão sobre o estado de natureza, dizendo se tratar de um assunto já bastante explorado pelos filósofos, quando procuraram os fundamento da sociedade e sentiram "a necessidade de voltar até o estado de natureza, mas nenhum deles chegou até lá" (ROUSSEAU, 1991, p. 235), sendo todos impedidos por uma série de equívocos: a suposição de que, já no estado de natureza, o homem tinha a noção do justo e do injusto, não se preocupando em saber se ele, nesse estado, teria a necessidade dessa noção ou se isso lhe fosse útil; a referência ao direito natural de cada um conservar o que lhe pertence, sem que houvesse explicação para o que seria pertencer. Por fim, diz Rousseau (1991, p. 235-236): "Outros dando inicialmente ao mais forte, a autoridade sobre os mais fracos, logo fizeram nascer o Governo, sem se lembrarem do empo que deveria decorrer antes que pudesse existir entre os homens o sentido das palavras autoridade e governo".

Considerando esses equívocos dos filósofos, Rousseau descreveu o estado de natureza, ressaltando as qualidades e as enfermidades do homem nesse estado e a domesticação como degeneração do homem natural quando posto em sociedade. Disse também que, no estado de natureza, o homem tinha os sentidos em comum com os animais, sendo as ideias provenientes desses sentidos, partindo deles os sentimentos e, portanto, a percepção. Mas, segundo Rousseau, a liberdade e a perfectibilidade são próprias do homem, já no estado de natureza. Assim a corrupção se inicia quando há alguma forma de interrupção da perfectibilidade pelo bloqueio da sua condição de ser livre.

O homem no estado de natureza era também amoral: não conhecia o bem nem o mal, o que já estava posto por Hobbes, como observa Arlei de Espíndola (2012, p. 36): “Antecipando Rousseau, Hobbes afirma que o homem, no começo dos tempos, está abaixo da esfera da moralidade, e por isso desconhece as diferenças entre o certo e o errado, o verdadeiro e o falso, o vício e a virtude". Mas, segundo Rousseau, Hobbes se equivoca ao

\begin{tabular}{|c|c|c|c|c|}
\hline Qenista Dialectus & Ano 8 & n. 15 & Agosto - Dezembro 2019 & p. $181-202$ \\
\hline
\end{tabular}


confundir o estado civil com o estado de natureza. Reportando-se a esses equívocos, afirma Olgária Matos (1978, p. 30): "O que Hobbes via no começo dos tempos, Rousseau vê no fim: o reino do egoísmo". Esse "reino do egoísmo" se faz notar quando, no estado civil, amor de si se converte em amor próprio: no estado de natureza, impulsionado pelo amor de si, o homem quer tudo para a espécie; no estado civil, impulsionado pelo amor próprio, ele quer tudo para si.

Assim, ao querer tudo para si, o homem recorre à ciência pela via da educação que se faz como hábito, para colocar tudo conforme os seus interesses, sobrepondo-se aos demais de sua espécie, passando da amoralidade para a imoralidade. A sociedade converte-se na oposição à natureza, a liberdade fica bloqueada e a perfectibilidade se faz como progresso da degradação humana. E isso ocorre quando homem cria a propriedade privada ao se dar conta de que sentia "necessidade do socorro do outro", ao tempo em que percebeu vantajoso um usufruir das "provisões para dois". A parir daí "desapareceu a igualdade, introduziu-se a propriedade, o trabalho tornou-se necessário e as vastas florestas transformaram-se em campos aprazíveis que se impôs regar com o suor dos homens e nos quais logo se viu a escravidão e a miséria germinarem e crescerem com as colheitas" (ROUSSEAU, 1991, p. 265).

Surge então a propriedade privada como o primeiro passo para o progresso da desigualdade entre os homens, que avançou em seu progresso com o surgimento da magistratura, a formação do Estado e, por último, como o despotismo. Com tudo isso ocorrendo, chegamos a um estado de civilização em que um homem domina, explora, oprime e reprime os outros em função de interesses próprios, não querendo "nada como o fez a natureza, nem mesmo o homem; tem de ensiná-lo para si, como um cavalo de picadeiro; tem que moldá-lo a seu jeito como uma árvore de seu jardim” (ROUSSEAU, 1995, p. 9).

\section{Conclusão}

Rousseau, ao voltar-se para a natureza em confronto com a sociedade no Discurso sobre as ciências e as artes e no Discurso sobre a desigualdade, depara-se com a degradação da natureza promovida pelo homem e ressaltada no desenvolvimento das ciências e da artes. Assim, ao invés de liberdade, igualdade e fraternidade, os homens, do mundo civilizado, apoderando-se da ciências, letras e artes, tolheram a liberdade e deixaram ausente a fraternidade. Assim, contrapondo-se ao pensamento iluministas, Rousseau entendeu que as

\begin{tabular}{|l|l|l|l|l|}
\hline Qovista Dialectus & Ano 8 & n. 15 & Agosto - Dezembro 2019 & p. $181-202$ \\
\hline
\end{tabular}


Luzes da Razão caminhavam em direção contrária daquilo que se reivindicava para uma nova sociedade, que haveria de se restabelecer com o fim do Antigo Regime. Por isso, já no Primeiro, a sua crítica social tem em vista a agressão à ruptura da natureza a partir da corrupção dos costumes como promoção dos vícios. No Segundo Discurso, isto se faz notar nos testemunhos dos fatos, mas também nos argumentos. Com outras palavras, Starobinski (1991, p. 288) diz que tudo se faz explícito, enunciando-se "com o aparato completo dos fatos, dos testemunhos, dos argumentos que o leitor exigente podia desejar", tendo apenas indicado "em uma bruma calorosa" pelo Primeiro Discurso.

Em resposta a Estanislau, Rousseau diz que "A primeira fonte do mal é a desigualdade". Essa resposta, lembrada por Starobinski, faz uma ponte entre exposto no Primeiro Discurso com o que expôs no Segundo: "Agora sente a necessidade de remontar mais longe de 'cavar até a raiz': essa desigualdade de que provém o mal, trata-se agora de ver de onde ela própria procede. Pode-se demonstrar a verdadeira origem do mal apenas examinando a origem da desigualdade" (STAROBINSKI, 1991, p. 288). Foi, pois, no Segundo Discurso que Rousseau aprofundou a discussão em torno do que fizera o homem com o progresso dos seus conhecimentos, desenvolvendo as ciências e das artes: ampliar a desigualdade que progredira com a propriedade privada.

Portanto, Rousseau aprofunda no Segundo Discurso a reflexão sobre a natureza exposta no Primeiro Discurso. Assim, a natureza torna-se a questão central para a compreensão da desigualdade moral e política entre os homens, que ele compreende como fonte de toda maldade humana no âmbito da civilização. Por último, tomando como referência a natureza, pensou na possibilidade da educação natural e negativa e em um novo contrato social.

\section{REFERÊECIAS:}

ARBOUSSE-Bastide, Paul Notas. In: ROUSSEAU, Jean-Jacques. Discurso sobre as ciências e as artes. Tradução Lourdes Santos Machado. São Paulo: Nova Cultural, 1999. (Coleção Os Pensadores - Rousseau, vol. II)

ARENDT, H. A condição humana. 10. ed. Rio de Janeiro: Forense Universitária, 2000.

CASSIRER, E. Antropologia filosófica: ensaio sobre o homem: introdução a uma filosofia da cultura humana. 2. ed. São Paulo: Mestre Jou, 1977.

\begin{tabular}{|c|c|c|c|c|}
\hline Rovista Dialectus & Ano 8 & n. 15 & Agosto - Dezembro 2019 & p. $181-202$ \\
\hline
\end{tabular}


DERATHÉ, Robert. Rousseau e a ciência política de seu tempo. Tradução por Natalia Maruyama. São Paulo: Barcarrola; Discurso Editorial, 2009. 663 p

DESCARTES, René. Discurso sobre o método. Tradução por J. Guinsburg e Bento Prado Júnior. São Paulo: Abril Cultural, 1973. (Coleção Os Pensadores). Tradução de: Les passions de l'âme.

DIONIZIO NETO, Manoel. Educação e liberdade em Jean-Jacques Rousseau. 2004. 340 f. Tese (Doutorado em Educação)-Universidade Federal de São Carlos, São Carlos, 2004.

ESPÍNDOLA, Arlei. A necessidade do estado em Hobbes e Rousseau. In: ESPÍNDOLA, Arlei (Org.). Rousseau: pontos e contrapontos. São Paulo: Bacarrolla, 2012.

ESPÍNDOLA, Arlei. A presença de Lucrécio no discurso sobre a desigualdade de JeanJacques Rousseau. In: ESPÍNDOLA, Arlei. Ensaios de leituras de escritos filosóficos clássicos em torno da reflexão ética política. São Leopoldo: Nova Harmonia, 2008.

ESPÍNDOLA, Arlei. Rousseau e Sêneca: natureza humana e crítica da sociedade. In: MARQUES, José Oscar de Almeida (Org.). Verdades e mentiras: 30 ensaios em torno de Jean-Jacques Rousseau. Ijuí: Unijuí, 2005. p. 275-295. (Coleção Filosofia; 15).

HOBBES, Thomas. Leviatã ou matéria, forma e poder de um Estado eclesiástico civil. Tradução por João Paulo Monteiro e Maria Beatriz Nizza da Silva. São Paulo: Nova Cultural, 1999. 496 p. (Coleção Os Pensadores).

JAUCOURT, Chevalier de. Igualdade natural. In: DIDEROT, Denis; D’ALEMBERT, Jean Le Rond. Verbetes políticos da Enciclopédia. Tradução por Maria das Graças de Souza. São Paulo: Discurso Editorial; Editora Unesp, 2006.

JAUCOURT, Chevalier. Lei natural. In: DIDEROT, Denis; D'ALEMBERT, Jean Le Rond. Verbetes políticos da Enciclopédia. Tradução por Maria das Graças de Souza. São Paulo: Discurso Editorial; Editora Unesp, 2006.

LÉVI-STRAUSS, Claude. As estruturas elementares do parentesco. Tradução por Mariano Ferreira. 2. ed. Petrópolis: Vozes, 1982. 540 p. (Série Antropologia, 9).

MACHADO, Lourival Gomes. Notas. In: ROUSSEAU, Jean-Jacques. Discurso sobre a origem e os fundamentos da desigualdade entre os homens. Tradução por Lourdes Santos Machado. 5. ed. São Paulo: Nova Cultural, 1991. 106 p. (Coleção Os pensadores, 6).

MACHADO, Lourival Gomes. Notas. In: ROUSSEAU, Jean-Jacques. Discurso sobre as ciências e as artes. Tradução Lourdes Santos Machado. São Paulo: Nova Cultural, 1999. (Coleção Os Pensadores - Rousseau, vol. II)

MATOS, Olgária C. F. Rousseau: uma arqueologia da desigualdade. São Paulo: M. G. Editores, 1978.

MONDIN, B. O homem, quem é ele? Elementos de antropologia filosófica. 13. ed. São Paulo: Paulus, 2008.

\begin{tabular}{|l|l|l|l|l|}
\hline Q Rovita Dialectus & Ano 8 & n. 15 & Agosto - Dezembro 2019 & p. $181-202$ \\
\hline
\end{tabular}


MONOD, Jacques. O acaso e a necessidade. Tradução por Bruno Palma e Pedro Paulo de Sena Madureira. 3. ed. Petrópolis: Vozes, 1976. 220 p. Tradução de: Hasard et la nécessité.

MONTESQUIEU, Charles de Secondat, Baron de. O espírito das leis. Tradução por Cristina Murachco. São Paulo: Martins Fontes, 1996. 851 p. (Paidéia). Tradução de: L’esprit des lois.

MORIN, Edgar. Os sete saberes necessários à educação do futuro. Tradução Catarina Eleonora F. da Silva e Jeanne Sawaya. 5. São Paulo: Cortez; Brasília-DF, UNESCO, 2002. Tradução de: Les sept savoirs nécessaires à l'éducation du futur.

MORIN, Edgar. O método 5: a humanidade da humanidade. Tradução por Jureemir Machado da Silva. 5. ed. Porto Alegre: Sulina, 2012.

MONTEIRO, João Paulo. Vida e obra. In: HOBBES, Thomas. Leviatã ou matéria, forma e poder de um Estado eclesiástico civil. Tradução por João Paulo Monteiro e Maria Beatriz Nizza da Silva. São Paulo: Nova Cultural, 1999. p.5-17. (Coleção Os Pensadores).

ROUSSEAU, Jean-Jacques. As Confissões. Tradução Wilson Louzada. Rio de Janeiro: Tecnoprint, 1965. (Clássicos de Bolso - Edições de Ouro - Águia de Ouro -AG 1219). Tradução de: Les confessions.

ROUSSEAU, Jean-Jacques. Discurso sobre a origem e os fundamentos da desigualdade entre os homens. Tradução por Lourdes Santos Machado. 5. ed. São Paulo: Nova Cultural, 1991. (Coleção Os pensadores, 6; p. 215-320).

ROUSSEAU, Jean-Jacques. Discurso sobre as ciências e as artes. Tradução por Lourdes Santos Machado. São Paulo: Nova Cultural, 1999. p.165-214. (Coleção Os Pensadores Rousseau, vol. II).

ROUSSEAU, Jean-Jacques. Emílio ou da educação. Tradução por Sérgio Milliet. 3. ed. Rio de Janeiro: Bertrand Brasil, 1995. 592 p. Tradução de: Émile; ou, De l'éducation.

SCIACCA, Michele Federico. História da filosofia: Antigüidade e Idade Média. Tradução por Luís Washington Vita. 3. ed. São Paulo: Mestre Jou, 1967. 260 p. v. I. Tradução de: La filosofia nel sou sviluppo storico.

STAROBINSKI, Jean. O discurso sobre a origem e os fundamentos da desigualdade. In: STAROBINSKI, Jean-Jacques Rousseau: a transparência e o obstáculo; seguido de sete ensaios sobre Rousseau. Tradução por Maria Lúcia Machado. São Paulo: Companhia das Letras, 1991. p. 288-309. Tradução de: Jean-Jacques Rousseau: la transparence et l'obstacle; suivi de sept essais sur Rousseau.

STAROBINSKI, Jean. Rousseau: a transparência e o obstáculo; seguido de sete ensaios sobre Rousseau. Tradução por Maria Lúcia Machado. São Paulo: Companhia das Letras, 1991. p. 288-309. Tradução de: Jean-Jacques Rousseau: la transparence et l'obstacle; suivi de sept essais sur Rousseau.

\begin{tabular}{|l|l|l|l|l|}
\hline Qonita Dialectus & Ano 8 & n. 15 & Agosto - Dezembro 2019 & p. $181-202$ \\
\hline
\end{tabular}


TOURAINE, Alain. Crítica da modernidade. Tradução por Elia Ferreira Edel. 3 ed. Petrópolis: Vozes, 1995. 432 p. Tradução de Critique de la Modernité. 